УДК 621.375 .4

\title{
НАГРУЗОЧНАЯ ЦЕПЬ ДЛЯ СВЕРХВЫСОКОЧАСТОТНОГО УСИЛИТЕЛЯ КЛАССА F
}

\author{
ЕФИМОВИЧ А. П., КРЫЖАНОВСКИЙ В.Г. ${ }^{1}$, КОВАЛЕНКО В. А. \\ ГИОФРЭ Р. ${ }^{2}$, КОЛАНТОНИО П. ${ }^{2}$, ДАНИЭЛИ Р. ${ }^{2}$ \\ ${ }^{1}$ Донеикий наичиональный университет, \\ Украина, Донеик, 83001, ул. Университетская, 24 \\ ${ }^{2}$ Римский университет Тор Вергата, \\ Италия, Рим, 00133, Via del Politecnico, 1
}

\begin{abstract}
Аннотация. Предложена методика построения и расчета нагрузочной цепи для сверхвысокочастотного усилителя мощности (УМ) класса F с добавлением третьей и пятой гармоник напряжения. Предложенная нагрузочная цепь позволяет скомпенсировать негативное влияние паразитных элементов транзистора (выходной емкости и выходной индуктивности) на работу УМ класса F. Также нагрузочная цепь позволяет снизить негативное влияние реальных свойств шунтирующего конденсатора в цепи питания и блокировочного конденсатора на импедансы, создаваемые нагрузочной цепью на кристалле транзистора. Для УМ класса F с добавлением третьей и пятой гармоник напряжения получена формула для расчета нагрузочного сопротивления транзистора на заданную выходную мощность
\end{abstract}

Ключевые слова: усилитель мощности класса F; нагрузочная цепь; паразитные элементы

\section{ВВЕДЕНИЕ}

При разработке транзисторных усилителей мощности (УМ) класса $\mathrm{F}$, работающих в диапазоне сверхвысоких частот (СВЧ), возникает необходимость учета реальных свойств транзистора и нагрузочных цепей, которые на практике снижают коэффициент полезного действия (КПД) усилителя [1-4]. Для УМ класca F важной задачей является учет таких паразитных элементов транзистора как выходная емкость и $C_{\text {вых }}$ и выходная индуктивность $L_{\text {вых }}$ [5-11]. Данные элементы образуют $L C$ цепь, которая не позволяет нагрузочной цепи создать импедансы на кристалле транзистора (параллельно $C_{\text {вых }}$ ) требуемые теорией [12].

В [6] предложена методика компенсации $C_{\text {вых }}$ и $L_{\text {вых }}$ для УМ класса $\mathrm{F}$ с добавлением третьей гармоники напряжения. Согласно [12] в таком усилителе теоретически возможен сто- ковый КПД $\eta_{c}=90,69 \%$ при условии, что на всех четных гармониках импедансы на кристалле транзистора равны нулю. На практике значение $\eta_{c}=90,69$ \% недостижимо, поскольку существует напряжение колена транзистора $V_{\text {кл}}$, которое в первую очередь ограничивает КПД усилителя. В [12] показано, что добавление дополнительной пятой гармоники напряжения способствует увеличению $\eta_{c}$ на 4,08\%.

В [5] предложена методика, позволяющая синтезировать нагрузочную цепь на сосредоточенных элементах, которая обеспечивает компенсацию негативного влияния $C_{\text {вых }}$ и $L_{\text {вых }}$ до $n$-ой гармоники. Однако в [5] установлено, что контролировать количество гармоник больше пяти достаточно сложно, поскольку в диапазоне СВЧ на всех гармониках выше пятой не удается получить требуемый импеданс из-за конструктивных ограничений и точности 